\title{
Publishing trends and productivity in insect taxonomy from 1946 through 2012 based on an analysis of the Zoological Record for four species-rich families
}

\author{
Yang LIU ${ }^{1, *}$, Christopher H. DIETRICH ${ }^{2}$, Susan M. BRAXTON ${ }^{3} \&$ Yang WANG ${ }^{4, *}$ \\ ${ }^{1,4}$ Key Laboratory of Resource Biology and Biotechnology in Western China (Ministry of Education) \\ and College of Life Science, Northwest University, Xi'an, Shaanxi Province, China. \\ ${ }^{1}$ Key Laboratory of Zoological Systematics and Evolution, Institute of Zoology, \\ Chinese Academy of Sciences, Beijing, China. \\ ${ }^{2}$ Illinois Natural History Survey, Prairie Research Institute, University of Illinois, \\ 607 Peabody Dr., Champaign, IL, USA. \\ ${ }^{3}$ University Library, University of Illinois, 1101 S. Goodwin Ave., Urbana, IL, USA. \\ ${ }^{4}$ College of Biology Pharmacy and Food Engineering, \\ Shangluo University, Shangluo, Shaanxi Province, China. \\ *Corresponding authors: liuyangent@nwu.edu.cn,wyang369@163.com \\ ${ }^{2}$ Email: chdietri@illinois.edu \\ ${ }^{3}$ Email: braxton@illinois.edu \\ ${ }^{1}$ urn:1sid:zoobank.org:author:D61F6467-2B5F-4DFF-A696-8A1ADE4741E0
${ }^{2}$ urn:1sid:zoobank.org:author:82FCB86C-54B4-456A-AE5E-D7847D271CB9
${ }^{3}$ urn:1sid:zoobank.org:author:873DECB8-F0F3-4E52-ADC0-7D9E597FE959
${ }^{4}$ urn:1sid:zoobank.org:author:2AAF93A0-E7B4-47DF-A346-EB8592BA926F
}

Abstract. Insect taxonomy is fundamental to global biodiversity research, but few studies have been conducted to track progress in this field using objective criteria. This study reports publishing trends in the taxonomy of four diverse, globally-distributed insect families from 1946 to 2012 to elucidate recent progress and the current status of insect taxonomy. Publications included in the Zoological Record online literature database were analyzed for Cicadellidae (leafhoppers), Miridae (plant bugs), Pyralidae (moths) and Staphylinidae (rove beetles). Data on numbers of new species, article length, species description length, authorship and collaborations, and taxonomic journals were extracted and compiled for each year. The results showed that (1) the number of taxonomic papers increased before 1980, followed by a steep decline with subsequent partial recovery; (2) the number of papers describing new species generally mirrored the trend in numbers of new species, suggesting no overall change in the proportion of larger, synthetic works (monographs) and more such work is encouraged; (3) the average number of new species described per publication decreased over the time period investigated, but with an increase in the average description pages per new species; (4) researchers from Europe and North America continue to produce the most taxonomic research on three of the four families, but the main center for Cicadellidae taxonomy has recently shifted to Asia; (5) collaboration among authors within and across continents has increased as indicated by increases in coauthored papers; and (6) journal 
prevalence differed for the four families and the top 10 most utilized journals for each family were given out for reference. Based on the analysis of the publication trend of the four families, we found that the overall trend toward increasing rates of species discovery is encouraging. But more human resources training and financial support on taxonomic work are required in order to complete a global faunistic inventory in a reasonable timeframe. Future study that conducts more in-depth and comprehensive analysis based on more families is required to reflect the overall trend of the insect taxonomy.

Keywords. Biodiversity, Cicadellidae, Miridae, Pyralidae, Staphylinidae.

Liu Y., Dietrich C.H., Braxton S.M. \& Wang Y. 2019. Publishing trends and productivity in insect taxonomy from 1946 through 2012 based on an analysis of the Zoological Record for four species-rich families. European Journal of Taxonomy 504: 1-24. https://doi.org/10.5852/ejt.2019.504

\section{Introduction}

Insects are the most diverse group of animals on the planet accounting for more than half of all known living organisms (Erwin 1982, 1997; Novotny et al. 2002; Chapman 2009). Despite remarkable efforts by insect taxonomists over the past three centuries, the task of discovering and describing Earth's insect fauna remains far from complete. Therefore, considerable ongoing taxonomic work is needed to provide a foundation for other biological research and classification as well as identification tools crucial to research on ecology and pest management in agriculture and forestry (Van Emden 1957) and ecosystem services (Tancoigne et al. 2014). In addition, progress in insect taxonomy is needed in order to achieve the Convention on Biodiversity's (CBD) Aichi Targets of the Strategic Plan for Biodiversity 2011-2020 (Pimm et al. 2014).

In response to concerns that the field of taxonomy is in crisis and that there are not enough taxonomists (e.g., Gaston \& May 1992; Godfray 2002; Hopkins \& Freckleton 2002), Joppa et al. (2011) analyzed specialized databases on eight taxa (birds, mammals, amphibians, spiders, flowering plants, the gastropod genus Conus, and the parasitic wasp superfamilies of Chalcidoidea and Ichneumonoidea), concluding that taxonomy is not disappearing, but transforming its practice (Joppa et al. 2011; Bacher 2012). Based on a study of the Zoological Record, Tancoigne \& Dubois (2013) concluded that current taxonomy is not meeting its objective of providing a complete scientific inventory and classification of the earth's living taxa ("taxonomic inertia"). They attributed taxonomic inertia to problematic scientific policy, inadequate funding and a shortage of taxonomists.

Although several recent studies examined trends in taxonomic publishing overall (Tancoigne et al. 2011; Tancoigne \& Dubois 2013; Grieneisen et al. 2014), only a few have attempted to measure recent trends in publication on insect taxonomy specifically, and these have focused on single insect families (Oberprieler et al. 2007; Dietrich 2013; Liu et al. 2018). Because of the importance of insects as the single largest component of global biodiversity, more information is needed on trends in insect species discovery. Here, we evaluate the recent trends and current status of the taxonomy of four diverse insect families by tracking research output, including rates of species discovery, scientific publication and international collaboration, to provide insight into the trends and current status of insect taxonomic work. To explore various factors that may affect publishing rates and rates of species discovery, we also examined the journal preference. We conducted the study by analyzing taxonomic articles indexed by the Zoological Record between 1946 and 2012, focusing on the four species-rich families Cicadellidae (Hemiptera) (with $>21000$ described species), Miridae (Hemiptera) (with $>11000$ described species), Pyralidae (Lepidoptera) (with $>6000$ described species), and Staphylinidae (Coleoptera) (with $>58000$ described species). These four families are distributed worldwide, encompass diverse assemblages in all biogeographic regions and are among the most species-rich families of Hemiptera, Lepidoptera and 
Coleoptera. We expect that trends observed for these groups may be generally representative of overall publishing trends and productivity in insect taxonomy. Because three of us (YL, CHD, YW) are most familiar with Cicadellidae, we were able to comment more extensively on trends for this family based on our intimate knowledge of the cicadellid literature. More details on these four families can be found in the Appendix.

\section{Material and methods}

The Zoological Record online database is the most comprehensive resource available that summarizes publishing output in animal biology, with a particular focus on taxonomic references, indexing the taxonomic literature and summarizing data for over 3.9 million publications from 1864 to the present. Unlike other literature databases, Zoological Record explicitly tracks nomenclatural acts such as descriptions of new taxa and other taxonomic name changes, tagging literature records with "systematics controlled terms" such as "sp. nov." (= new species), "syn. nov." (= new synonym), etc. Thus, it provides a convenient means for summarizing taxonomic output and tracking publishing trends in animal taxonomy. Our study focused on publications in insect taxonomy for the time frame 1946 to 2012 (after World War II to the date of study). We used the 2012 cut-off date for our analysis because the time lag in indexing publications may yield less complete data for more recent years. This 66 -year period covers contributions from biologists/entomologists of two to three generations and illustrates recent tendencies and transitions in this field.

Using literature records downloaded from the Zoological Record, we calculated the values of variables that we considered representative of various aspects of taxonomic output for the four insect families, including numbers of new species described, numbers of papers published, and numbers of pages published.

The search procedure was as follows. We first searched under "topic" for the name of each family (e.g., "Cicadellidae") with the range of years limited to 1946-2012 to retrieve all papers mentioning that family name. To smooth the data and make long-term trends more obvious, all variables were the 5-year running averages (e.g., the variable value for 1950 was the averaged values for years from 1946 to 1950,1951 was the average of 1947-1951, etc.). We then filtered the results by selecting five systematics controlled terms ("sp. nov." new species, "key to species", "gen. nov." new genus, "comb. nov." new combination, "syn. nov." new synonym) and selecting "Refine" to exclude papers without nomenclatural acts or other taxonomic content. We verified the records by mainly checking the title and abstract (occasionally the whole paper if more information was required) one by one to ensure that the paper focused on the family of interest (not, for example, on parasites or symbionts of that group). The remaining records were then exported as tab-delimited text files so they could be imported into an Excell spreadsheet for further analysis. We then summarized number of new species by year, number of articles with new species, number of papers published by authors from each continent (Europe, North America, South America, Africa, Asia, Australia), number of co-authored papers (papers with more than one author, for analysis of collaboration trends), number of co-authored papers with authors from different continents (papers with authors from two or more continents, to examine trends in international collaboration), paper length (pages), number of total published pages by year, and numbers of taxonomic publications in each journal. In some taxonomic papers, authorship of nomenclatural acts (e.g., new species descriptions) is different from the authorship of the paper. However, because this information is difficult to obtain without manually checking each nomenclatural act in every paper, and there are no generally accepted rules for assigning authorship to such acts in insect taxonomy, we did not attempt to distinguish the contributions of co-authors.

Determination of the continent from which papers came was based on the corresponding author's address or first author if the corresponding author was not identified. The categorization of countries 
to six continents is based on the most updated map of the continents (https://www.mapsofworld.com/, accessed on 7 Nov. 2017). Russia is attributed to the European continent, but some former Soviet Union countries are attributed to Asia. For authors who migrated from one continent to another during the publication process, the continent was attributed based on their original corresponding address where they initiated the work prior to their relocation. We focused on documenting collaborations involving authors from different continents, rather than different countries on a single continent, because trends in the former may more closely reflect the impacts of recent government programs to promote collaboration between scientists in developing countries (e.g., in Asia and South America) with scientists in developed countries (e.g., Europe and North America).

\section{Results}

Our literature search yielded 2425 published papers (including books), including at least one of the systematics controlled terms during the period 1946 to 2012 for Cicadellidae, 2980 for Miridae, 4683 for Pyralidae and 4765 for Staphylinidae.

\section{New species described}

Three of the four insect families (all except Pyralidae; Fig. 1A) show clear peaks spanning roughly from the mid-1960s to the mid-1980s or 90s followed by steep declines. For Cicadellidae, the sharp decline following a peak from middle 1980s to middle 1990s coincided with the retirement or death of leading taxonomic researchers (e.g., H.D. Blocker, D.M. Delong, J. Dlabola, L.W. Hepner, W.J. Knight, R. Linnavuori, M.S.K. Ghauri), many of whom began their careers during the post-WWII period in the USA and Europe (Dietrich 2013). More recent positive trends in new species discovery began around 2000 in all four families, but only three of the four families (not Miridae) continue to increase, with the most dramatic increase occurring in Staphylinidae, for which a new high was reached in 2012. Pyralidae also reached a new high in number of new species described in 2012. However, the numbers of new species described per year in Cicadellidae and Miridae have not yet reached their previous peaks and in 2012 were only near the overall average for the time period considered.

\section{Publications containing new species descriptions}

The trend in numbers of publications containing new species (Fig. 1B) is similar to that for new species described. This indicates a relatively constant number of new species per publication, on average, over time, with a few exceptions. In Cicadellidae, for example, there were several large monographs each comprising $>100$ new species descriptions published in the 1970s and 80s (Nielson 1975, 1977, 1979, 1982; Hamilton 1983; Young 1977, 1986), accounting for the smaller size of the peak in publications during that time relative to the number of species described.

Since 2010, the number of articles with new species for Cicadellidae has exceeded its previous peak in the 1980s, although the number of new species described per year remains far below its historic peak, reflecting the fact that more short papers (with a few new species descriptions per publication) and relatively few large monographs have been published recently, with the latter often synthesizing data for previously described taxa rather than including large numbers of new species (e.g., Dmitriev \& Dietrich 2010; Zahniser \& Dietrich 2013). Trends observed in the other three families were similar. There is a positive correlation between the number of new species and the number of articles with new species with $\left(\mathrm{R}^{2}=0.85\right.$ using data from Fig. 1$)$.

Although species described per taxonomist is an important metric, because it is usually difficult to account for the contributions of co-authors to the new species described in a taxonomic article, we measured the new species described per article instead. As shown in Fig. 2, the new species described per taxonomic article declines in general $\left(\mathrm{R}^{2}=0.7\right)$. However, the average length of new species descriptions shows 
LIU Y. et al., Publishing trends and productivity in insect taxonomy
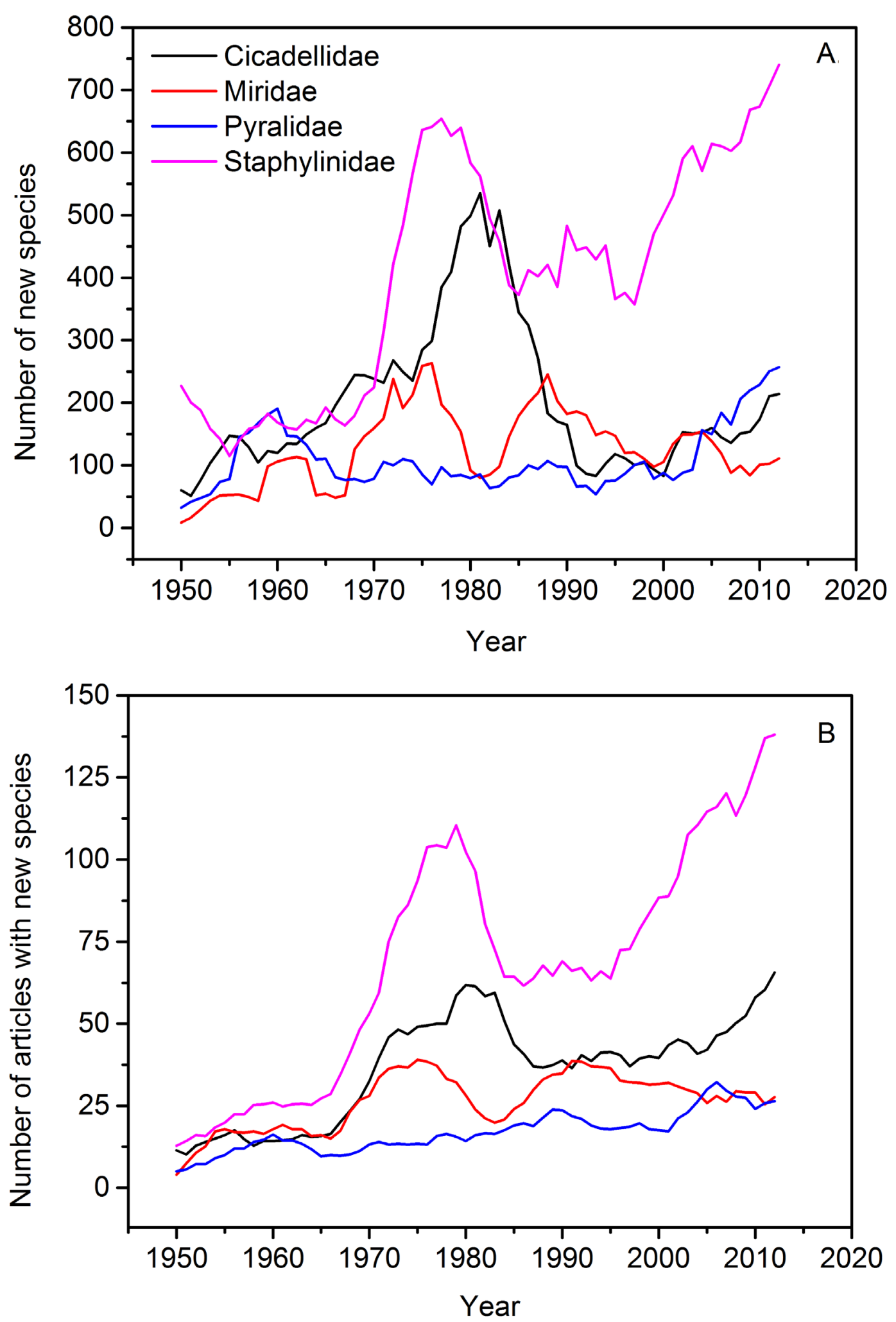

Fig 1. Time series of newly described species for the families Cicadellidae, Miridae, Pyralidae and Staphylinidae between 1946 and 2012. A. Number of new species. B. Number of articles with new species. 
an increasing trend (Fig. 3). This reflects the fact that recent taxonomic works include more detailed descriptions and high quality photographs or other illustrations that enable more accurate identification. Earlier studies often provided minimal numbers of line drawings of diagnostic structures. Development of low-cost, high-quality digital photography now enables the inclusion of color habitus photos in addition to detailed illustrations of genitalia, etc.

\section{Distribution of total and average article length (in pages)}

As illustrated in Fig. 4, there is a positive trend in total pages published for all four insect families over the entire time period examined, more or less similar to that observed for numbers of papers and numbers of species described (Fig. 1).

The average article length in publication pages is presented in Fig. 4B. All four families show large fluctuations in article length, a general increasing trend in Pyralidae and a decreasing one in Cicadellidae since 1970 are observed. However, the average length of new species descriptions increased over the period investigated as shown in Fig. 3. Compared to the other three families, it is evident that the proportion of comprehensive revisionary studies for Cicadellidae is decreasing as smaller taxonomic papers account for the majority of new species described in recent years.

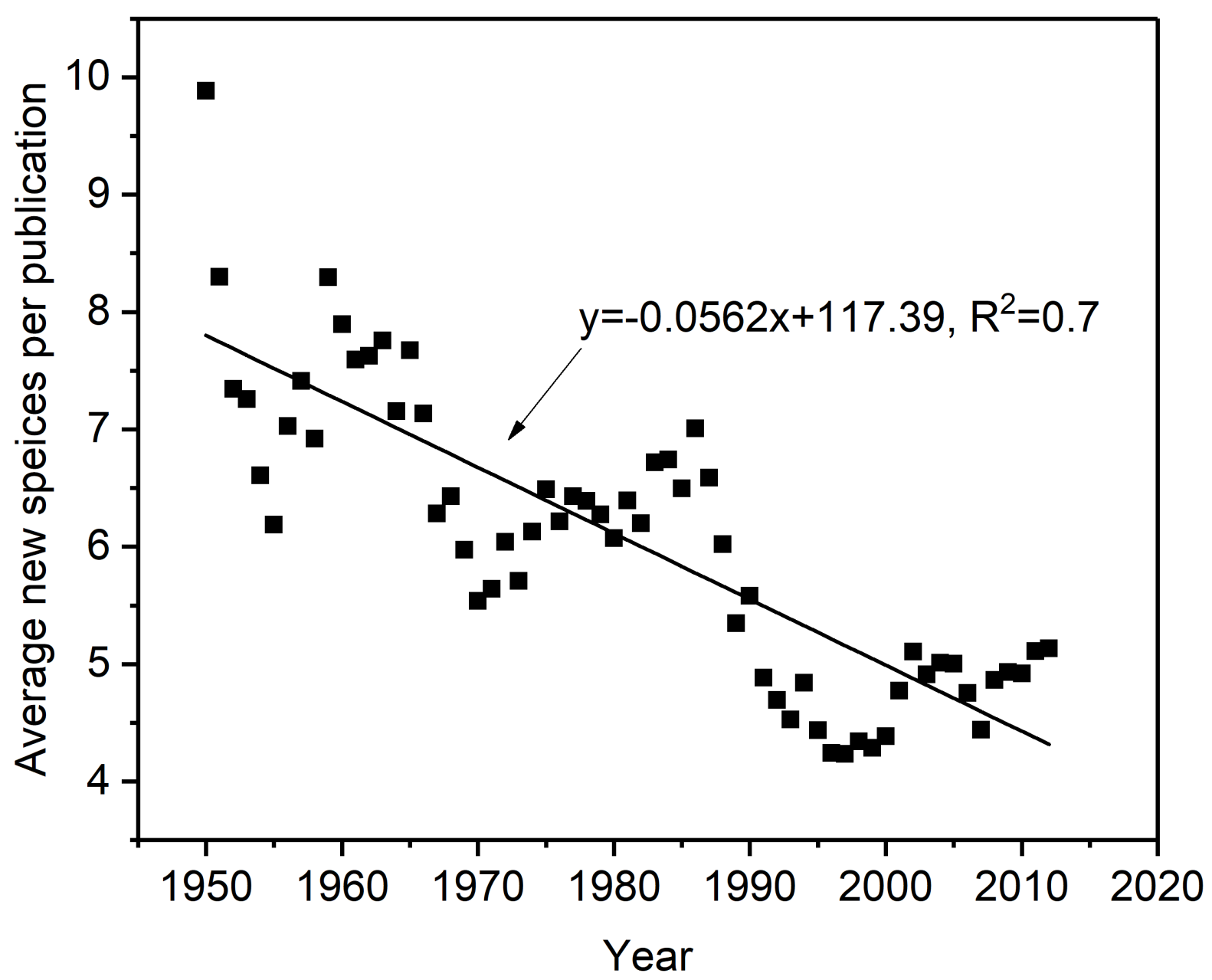

Fig 2. Average new species described per article (Cicadellidae, Miridae, Pyralidae and Staphylinidae combined) from 1946 to 2012. 


\section{Number of papers published by authors from each continent}

As can be seen from Fig. 5, for the time period covered, Europe and North America were the dominant contributors of taxonomic articles while Africa and Australia contributed relatively few papers. European and North American authors continued to dominate species discovery in Miridae and Staphylinidae (Fig. 5B, D).

Since 1987, Asian authors have contributed the most papers on Cicadellidae (Fig. 5A) and Asian contributions on Pyralidae also briefly surpassed those from other continents in the mid-2000s but this trend has not continued (Fig. 5C).

As shown in Fig. 5B, the contributions of authors from South America to the taxonomy of Miridae is significant, with three distinct peaks in the 1950s, 70s and early 90s, but contributions have been flat since 2000. For instance, the number of publications by authors from South America exceeded that from North America in 1975 and exceeded that from both North America and Europe in 1990. A trend toward increasing contributions on Cicadellidae from South America beginning in the 1980s is also noteworthy (Fig. 5A). South American contributions on the other two families (Pyralidae and Staphylinidae) have been negligible, with European, North American and Asian authors predominating.

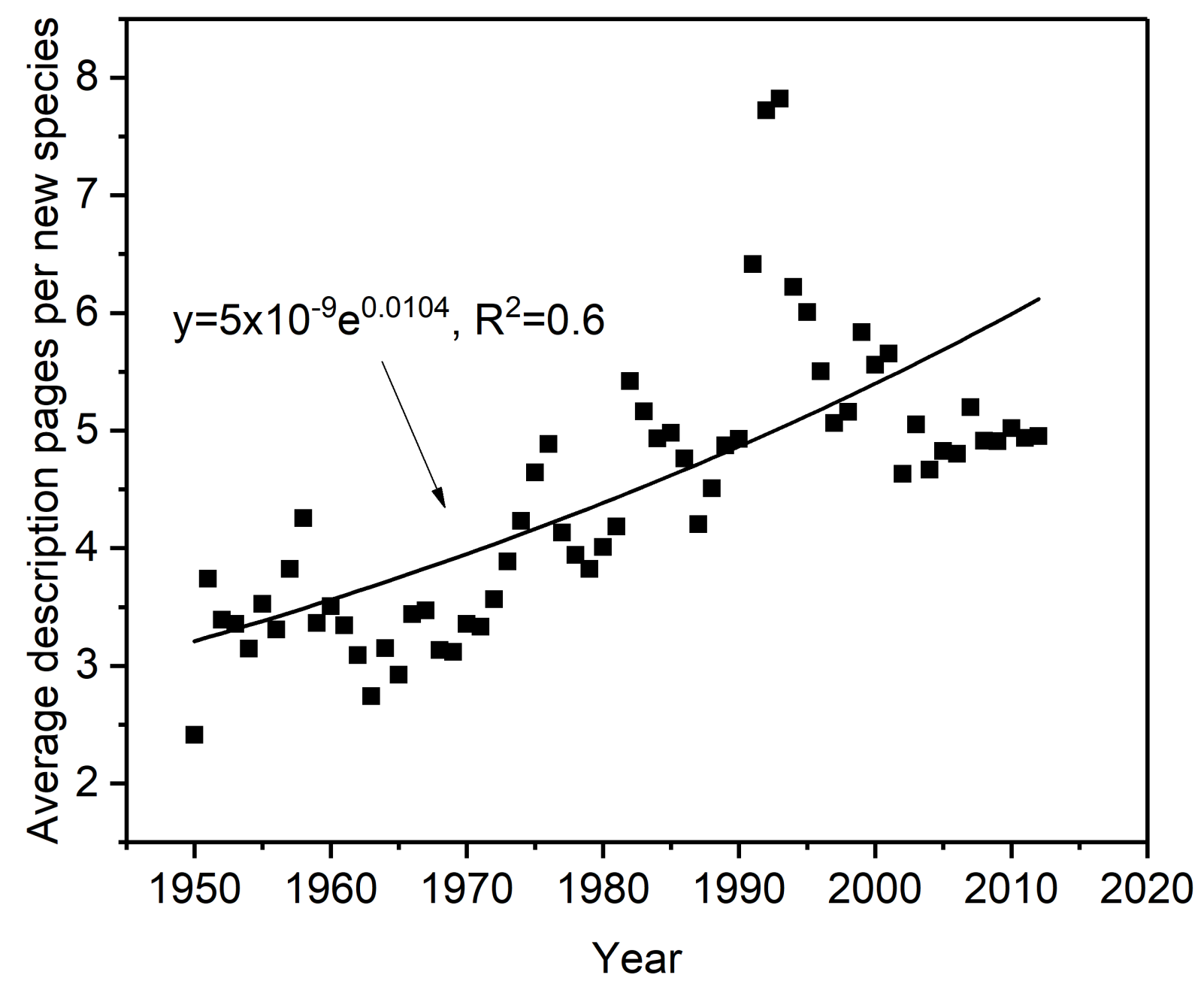

Fig 3. Average page length of new species descriptions (Cicadellidae, Miridae, Pyralidae and Staphylinidae combined) between 1946 and 2012. 

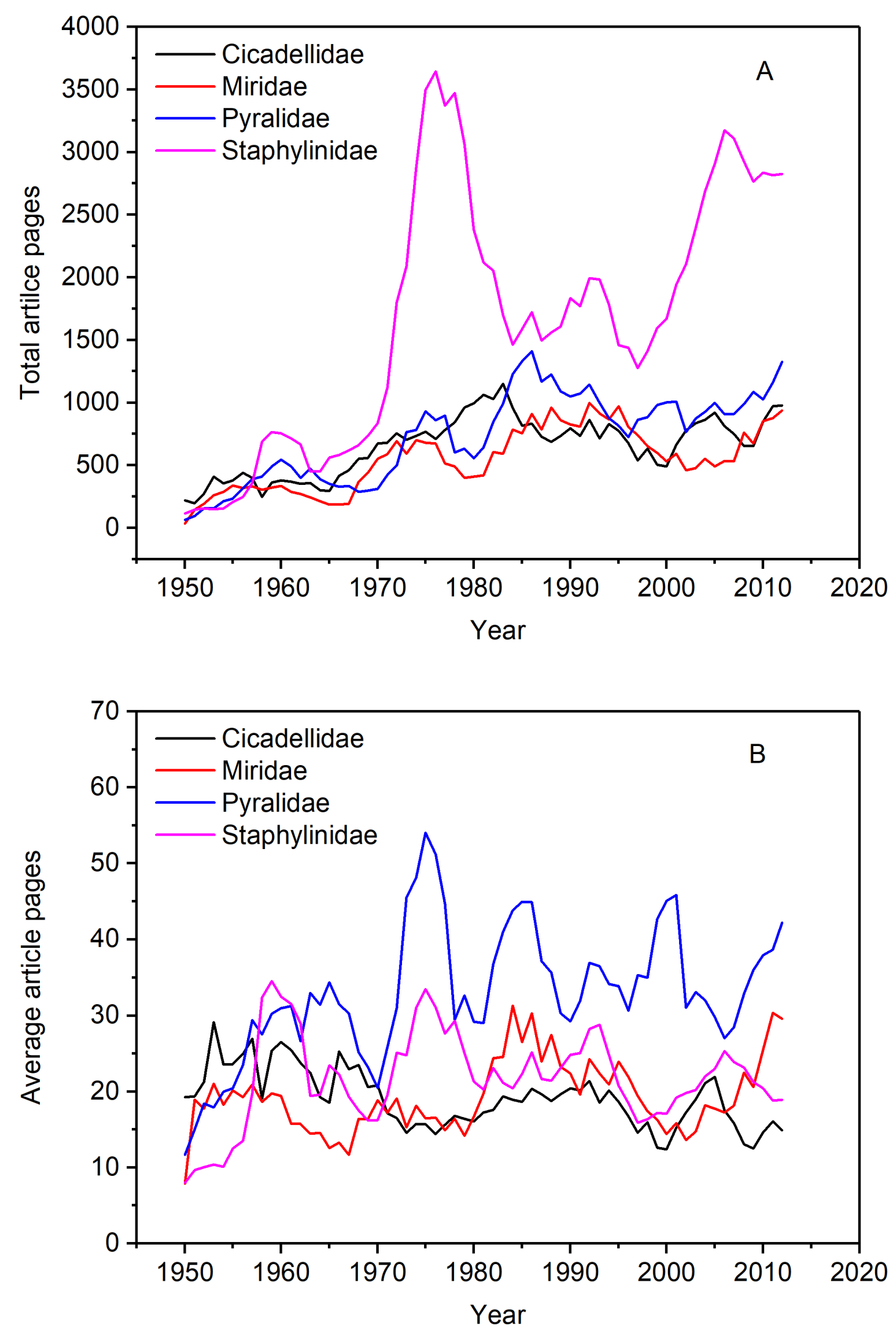

Fig 4. Total and average article length for for papers on the four families of Cicadellidae, Miridae, Pyralidae and Staphylinidae between 1946 and 2012. 


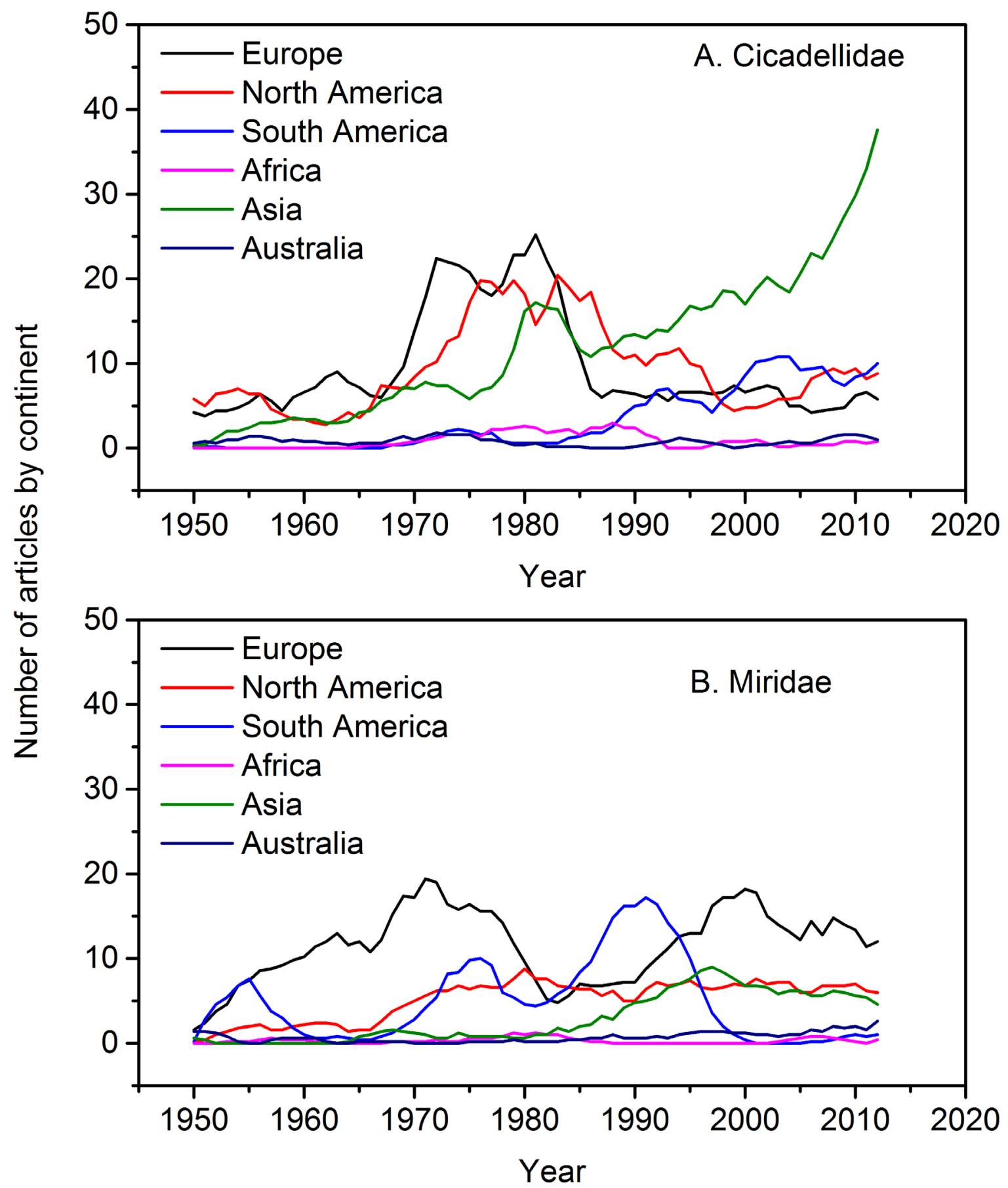

Fig 5 (continued on next page). Number of articles published by continent (Europe, North America, South America, Africa, Asia and Australia) between 1946 and 2012. A. Cicadellidae. B. Miridae. C. Pyralidae. D. Staphylinidae. 



Fig 5 (continued from previous page). Number of articles published by continent (Europe, North America, South America, Africa, Asia and Australia) between 1946 and 2012. A. Cicadellidae. B. Miridae. C. Pyralidae. D. Staphylinidae. 
LIU Y. et al., Publishing trends and productivity in insect taxonomy

There is a marked, albeit uneven, increase overall in recent contributions from Asia and South America. Just two laboratories in China were responsible for 414 papers on Cicadellidae during the most recent 15 year period examined: Northwest A\&F University (189 articles) and Guizhou University (225 articles). Brazil accounts for the distinct, but more modest, increase in contributions from South America for three of the four families during the same time period. However, the recent increases in numbers of papers from Asia and South America did not yield proportionately greater additions of new species.

\section{Distribution of co-authored articles}

Figure 6 shows the number of total articles and co-authored articles. Overall, there is at least a slight trend toward increasing co-authorship (Figs 7-8), but this trend is substantial in Cicadellidae. There were 414 first authors for the 2425 Cicadellidae articles, with an average of 5.8 papers published by each author between 1946 and 2012. Average number of authors per publication also increased steadily over the time period examined with an average of 1.14 authors per publication from 1946-1950 but 2.25 for 2011-2015. The most prolific authors (in number of papers published as first author or co-author) are listed in Table 1. For Cicadellidae, much of the increase in co-authored papers is attributable to the top three most prolific authors (Z.Z. Li, D.M. DeLong and Y.L. Zhang) co-authoring papers with their numerous students.

Professors Li and Zhang currently lead large laboratories in China that employ many junior faculty members, postdoctoral fellows and graduate students, substantial numbers of whom continue to publish on Cicadellidae taxonomy. In contrast, although the most prolific author in the USA, Prof. DeLong, trained $>15$ graduate students who co-authored papers with him, only one (P. Freytag) has continued to publish independently on leafhopper taxonomy.

Table 1 shows the distribution of papers co-authored by researchers from different continents and reflects a trend toward increased international collaboration. Such collaboration among authors on different continents increased, beginning in 1995-2000, and remains above or near historic highs for all groups, but has shown particularly dramatic recent increases for Cicadellidae and Staphylinidae. This may reflect the impacts of recent government-funded programs (e.g., in China and several South American countries) that promote collaboration between scientists in developing countries and their colleagues from Europe or North America. For example, much recent Cicadellidae research at the Northwest A\&F University was funded by the National Natural Science Foundation of China, China Scholarship Council, and Ministry of Science and Technology of China that explicitly involved collaborations with scientists in the USA and Europe (Cao et al. 2018; Feng et al. 2018; Wang et al. 2017; Xue et al. 2017a, 2017b, 2017c, 2017d).

\section{Distribution of articles by journal}

Figure 9 illustrates the top 10 journals that published articles for each of the four families over the past 66 years. Zootaxa was the most utilized journal overall but, among the four examined insect families, was only the most often utilized journal for Cicadellidae (Fig. 9A). The number of Cicadellidae papers published in Zootaxa sharply increased from 1 in 2003 to 22 in 2008 and 45 in 2012. The popularity of this journal may be attributed to lack of page charges and its status as an international journal specifically focusing on taxonomy. The most often utilized journals for the other three families were three different journals, i.e., Revista Brasileira de Biologia for Miridae (Fig. 9B), Proceedings of the Entomological Society of Washington for Pyralidae (Fig. 9C) and Linzer Biologische Beiträge for Staphylinidae (Fig. 9D). These choices apparently reflect the institutional affiliations and personal preferences of the leading authors focused on these groups. 


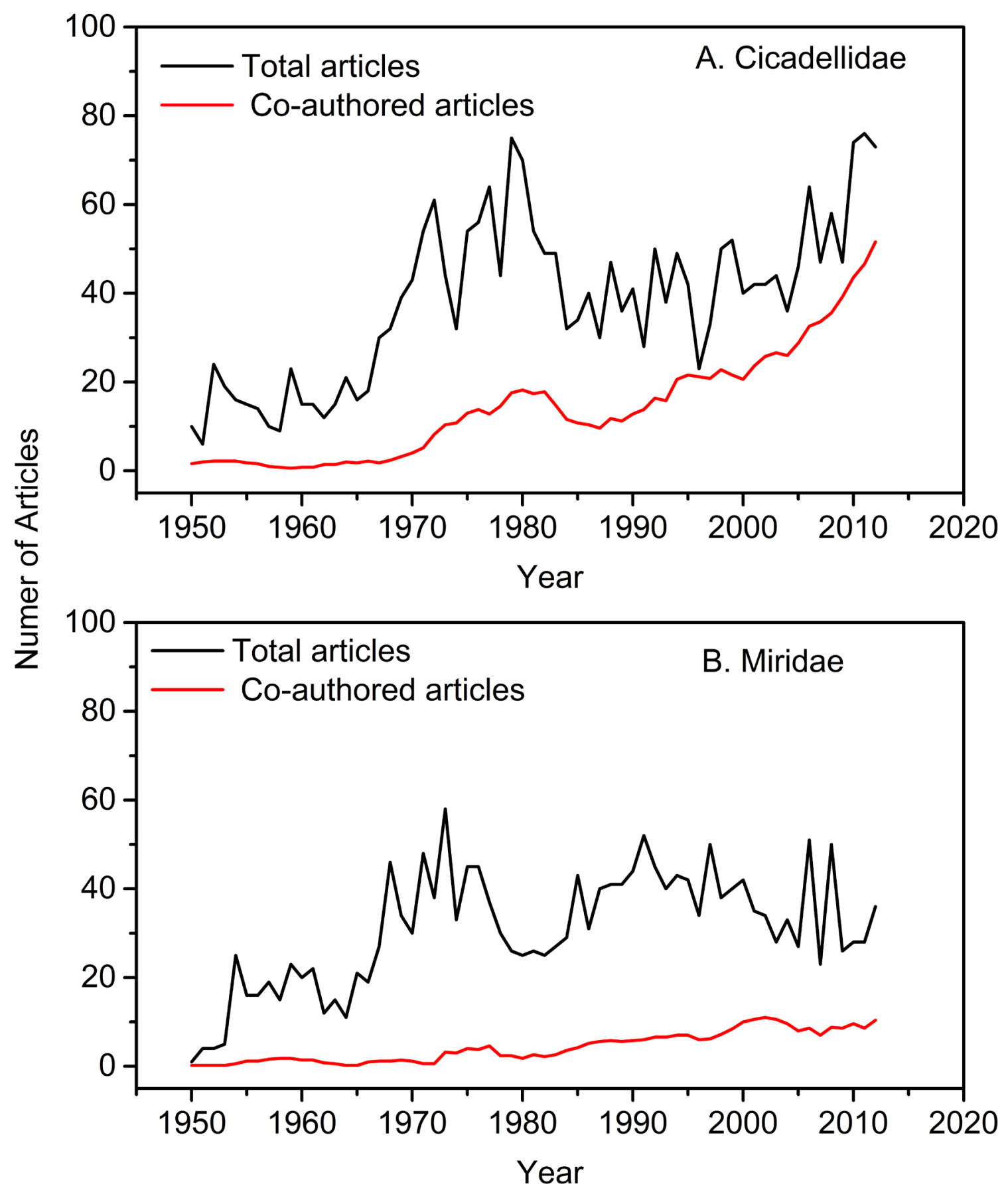

Fig 6 (continued on next page). Number of total articles and co-authored articles from 1946 to 2012. A. Cicadellidae. B. Miridae. C. Pyralidae. D. Staphylinidae. 


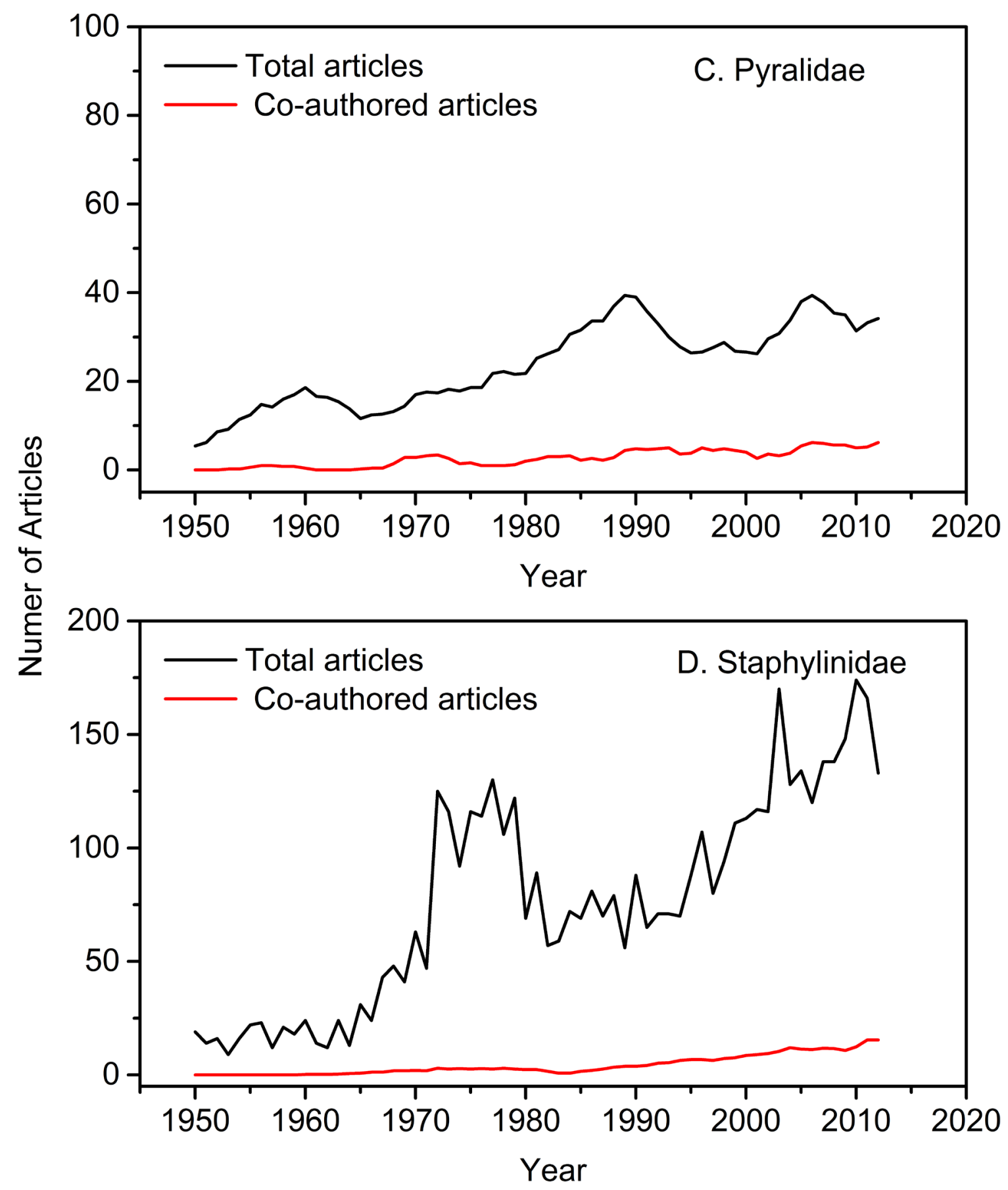

Fig 6 (continued from previous page). Number of total articles and co-authored articles from 1946 to 2012. A. Cicadellidae. B. Miridae. C. Pyralidae. D. Staphylinidae. 
It is noteworthy that Zootaxa was only founded in 2001, but it has published nearly a quarter of the new taxa of all species indexed in Zoological Record since 2009. Prior to the establishment of Zootaxa, most taxonomic papers were published in regional journals related to the institutional affiliation, geographic location or focal taxon of the author. Such venues continue to be heavily utilized by taxonomists working on certain insect groups, including the groups examined here.

\section{Discussion}

\section{Perspectives}

A taxonomic impediment (e.g., human expertise, global knowledge, and funding) to biological research has been recognized as an apparent problem for at least the past three decades (Rodman \& Cody 2003). Debate regarding the nature of the problem, its severity, and the impacts of recent government initiatives is ongoing (e.g., Joppa et al. 2011; Tancoigne et al. 2011; Bacher 2012; Tancoigne \& Dubois 2013; Grieneinsen et al. 2014; Paknia et al. 2015).

Our analysis of taxonomic articles over the period of 1946-2012 indexed in the Zoological Record for four large, globally distributed insect families indicates that progress in documenting the world fauna of these groups has been uneven in the post-WWII era, with distinct peaks in productivity (as measured by papers and pages published, in addition to new species discovered) during the 1970s and 80s followed by substantial declines for three of the four families (Fig. 1) substantiating earlier calls (e.g., GTI and PEET) for more training in basic taxonomy (Rodman \& Cody 2003). As of 2012, two of the four groups (Staphylinidae and Pyralidae) had well surpassed their previous high points in terms of new species

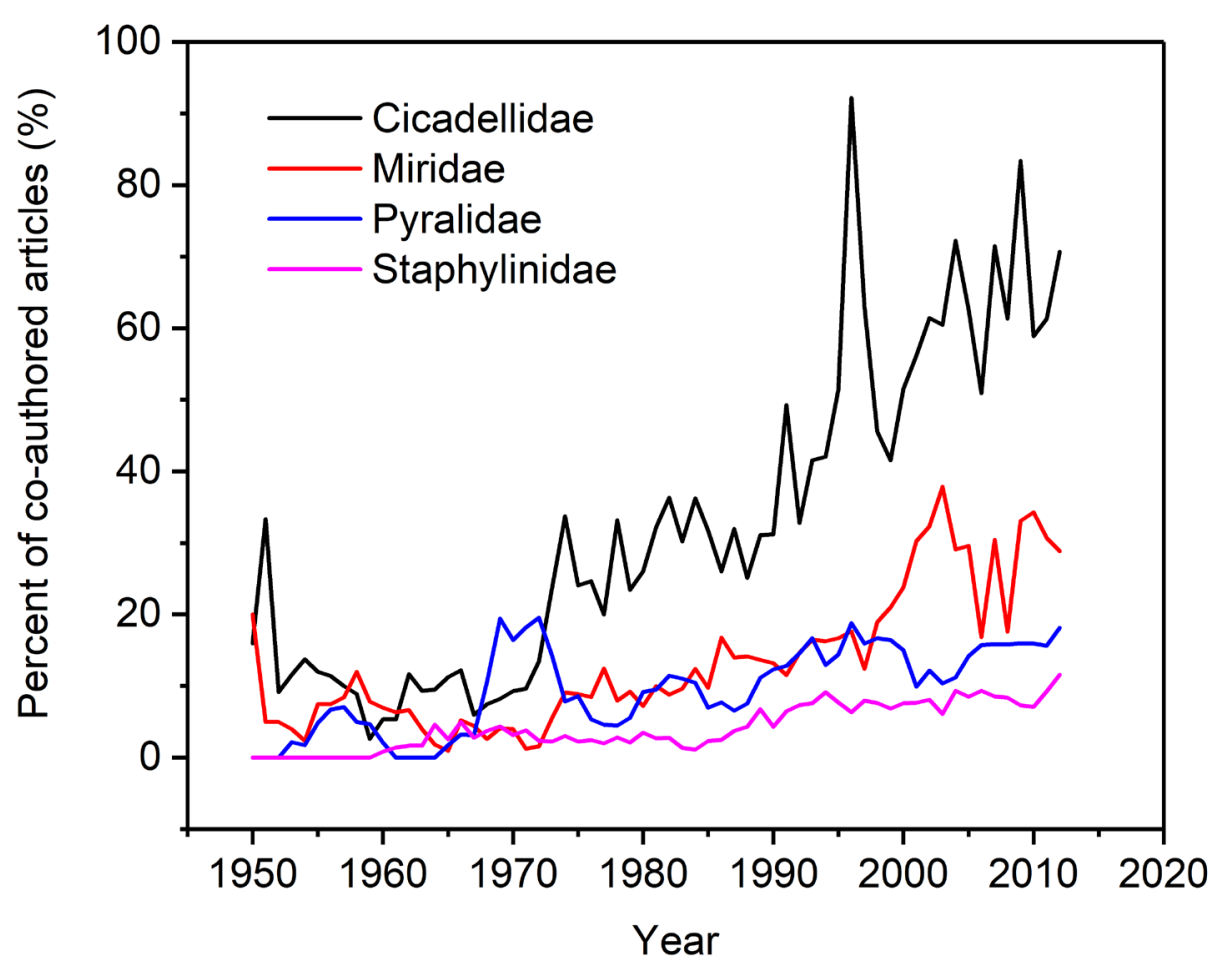

Fig. 7. Percentage of articles with co-authors from 1946 to 2012. 
described per year, but the other two families (Cicadellidae and Miridae) remained near the yearly average over the 66-year period considered.

Overall taxonomic productivity, as measured by new species described, peaked around 1980, but subsequently declined substantially for three of the four families examined. More recent increases in productivity beginning in the mid-90s may reflect the employment of new technologies (e.g., cybertaxonomic methods and infrastructures, integrative taxonomy), increased financial support for basic taxonomy, and training of a new generation of researchers (Dietrich \& Dmitriev 2016). These increases have occurred along with an increase in the average length of new species descriptions, suggesting that quality, at least in terms of the amount of data provided per species, is increasing along with the quantity of new species discovered.

These increases may be accounted for, at least in part, by government-funded programs in several countries established to support and promote basic biodiversity science, including taxonomy. For example, the Global Taxonomy Initiative (GTI) of the Convention on Biological Diversity (CBD) supports taxonomic training in developing countries. The U.S. National Science Foundation's Partnerships for Enhancing Expertise in Taxonomy (PEET) program, established in 1995, supported taxonomic training in diverse but less studied groups (Rodman \& Cody 2003) and, more recently, the NSF ARTS (Advancing Revisionary Taxonomy and Systematics) program has continued to support biodiversity inventories and comprehensive revisionary studies that incorporate innovative methods (Gaston \& O’Neill 2004). CETAF (Consortium of European Taxonomic Facilities) encourages programs aimed toward taxonomic synthesis in Europe (including the EU funded Synthesis grants and the CETAF DEST courses in taxonomy). The IPBES-6 (The Intergovernmental Science-Policy Platform on Biodiversity

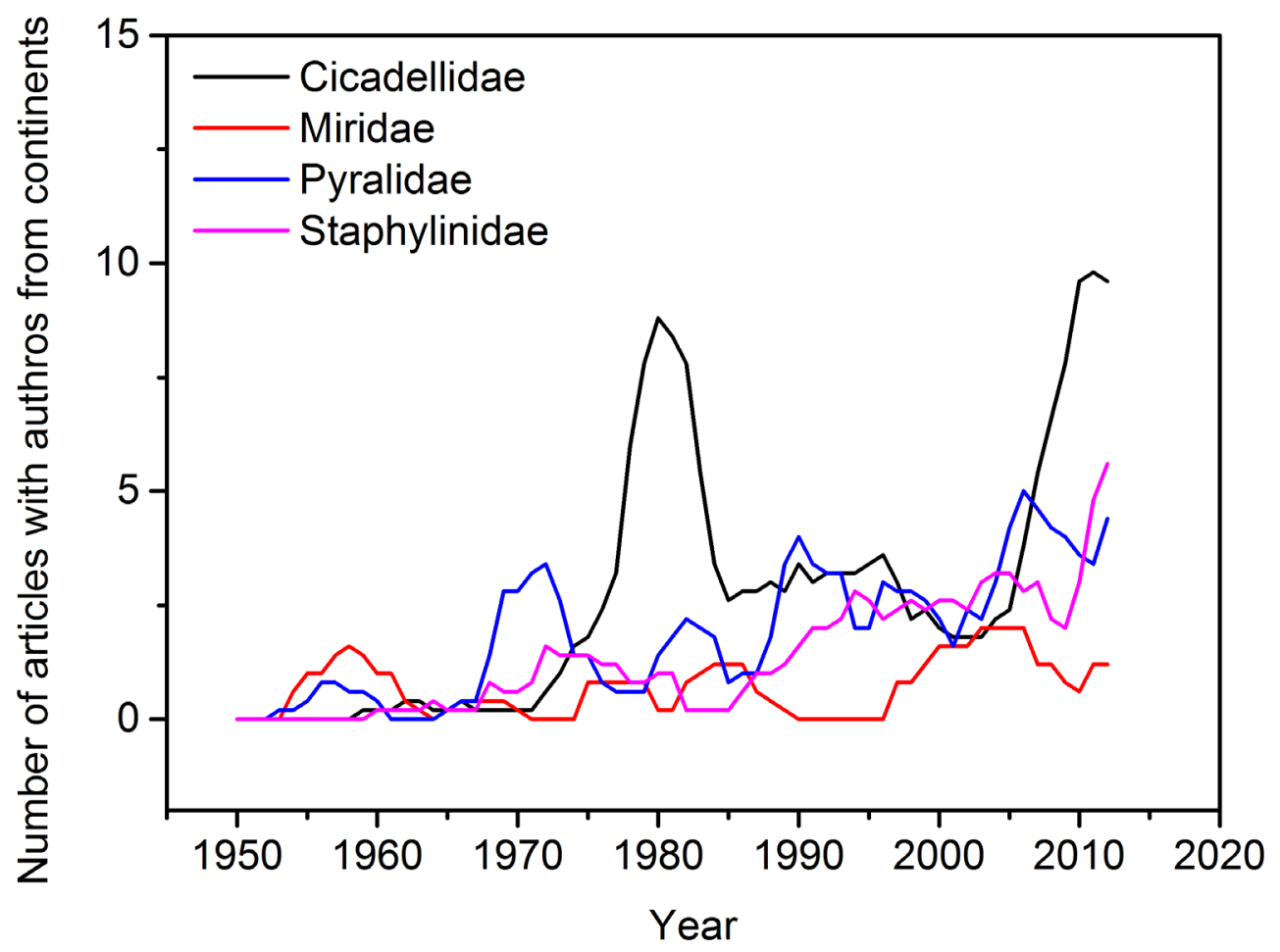

Fig 8. Number of co-authored papers with authors from different continents from 1946 to 2012. 
Table 1. Top 20 most productive authors for the four families (Cicadellidae, Miridae, Pyralidae Staphylinidae).

\begin{tabular}{|l|lllllll|}
\hline \multicolumn{2}{c}{ Cicadellidae } & \multicolumn{2}{c}{ Miridae } & \multicolumn{2}{c}{ Pyralidae } & \multicolumn{2}{c}{ Staphylinidae } \\
\multicolumn{1}{c}{$\begin{array}{c}\text { TOP } 20 \\
\text { authors }\end{array}$} & $\begin{array}{c}\text { Number } \\
\text { of papers }\end{array}$ & \multicolumn{1}{c}{$\begin{array}{c}\text { TOP 20 } \\
\text { authors }\end{array}$} & $\begin{array}{c}\text { Number } \\
\text { of papers }\end{array}$ & \multicolumn{1}{c}{$\begin{array}{c}\text { TOP 20 } \\
\text { authors }\end{array}$} & $\begin{array}{c}\text { Number } \\
\text { of papers }\end{array}$ & $\begin{array}{c}\text { TOP 20 } \\
\text { authors }\end{array}$ & $\begin{array}{c}\text { Number } \\
\text { of papers }\end{array}$ \\
\hline Li Z.Z. & 186 & Carvalho J.C.M. & 378 & Munroe E. & 98 & Puthz V. & 470 \\
DeLong D.M. & 175 & Wagner E. & 178 & Li H.H. & 56 & Pace R. & 337 \\
\hline Zhang Y.L. & 162 & YasunagaT. & 97 & Leraut P. & 53 & Assing V. & 312 \\
\hline Dworakowska I. & 111 & Linnavuori R. & 95 & Roesler R.U. & 50 & Smetana A. & 207 \\
\hline Freytag P.H. & 96 & Henry T.J. & 77 & Yamanaka H. & 47 & Bordoni A. & 204 \\
\hline Nielson M.W. & 78 & Gorczyca J. & 63 & Solis M.A. & 45 & Coiffait H. & 165 \\
\hline Viraktamath C.A. & 77 & Kerzhner I.M. & 56 & Amsel H.G. & 40 & Kistner D.H. & 160 \\
\hline Linnavuori R. & 73 & Schwartz M.D. & 56 & Neunzig H.H. & 40 & Lobl I. & 139 \\
\hline Cavichioli R.R. & 67 & Zheng L.Yi. & 50 & Inoue H. & 34 & Scheerpeltz O. & 127 \\
\hline Dlabola J. & 67 & Costa L.A.A. & 44 & Viette P. & 34 & Watanabe Y.i & 123 \\
\hline Webb M.D. & 58 & Schaffner J.C. & 41 & Song S.M. & 30 & Li L.-Z. & 105 \\
\hline Hamilton K.G.A. & 44 & Schuh R.T. & 41 & Spiedel W. & 30 & Naomi S.-I. & 87 \\
\hline Mejdalani G.L.F. & 43 & Kelton L.A. & 40 & Bleszynski S. & 29 & Klimaszewski J. & 76 \\
\hline Anufriev G.A. & 42 & Cherot F. & 39 & Mutuura A. & 26 & Hromadka L. & 75 \\
\hline Dietrich C.H. & 40 & Josifov M. & 37 & Nuss M. & 24 & Fagel G. & 68 \\
\hline Kuoh Chung L. & 40 & Ferreira P.S.F. & 36 & Kirpichnikova V.A. & 23 & Campbell J.M. & 62 \\
\hline Dai R.H. & 38 & Liu G.Q. & 35 & Rose H.S. & 23 & Zhao M.-J. & 61 \\
\hline Cai P. & 36 & Herczek A. & 34 & Yoshiyasu Y. & 22 & Schillhammer H. & 55 \\
\hline Ghauri M.S.K. & 36 & Ribes J. & 33 & Maes K.V.N. & 21 & Last H.R. & 54 \\
\hline Zanol K.M.R. & 36 & Carpintero D.L. & 29 & Bassi G. & 19 & Schuelke M. & 53 \\
\hline
\end{tabular}

and Ecosystem Services) promotes research on biodiversity and ecosystem services. Similar programs in developing countries include the scholar and PhD Joint Training Program of the China Scholarship Council (Wang et al. 2017), the Ciência Sem Fronteiras program in Brazil, and similar programs in Argentina (CONICET), Colombia (Colciencias). These programs explicitly promote international training and collaboration in various disciplines including biodiversity research.

As indicated by our analysis, the main centers of taxonomic research for three of the four families examined remain in Europe and North America, as they were historically, but contributions from Asia and South America have increased in recent years and remain on an upward trajectory. For Cicadellidae, Dietrich (2013) noted a recent shift from Europe and North America to Asia as the main center for research, confirmed by our analysis.

There are several possible reasons for such shifts. As noted by Dietrich (2013) the recent decline in predominance of Cicadellidae researchers in the USA and Europe resulted from retirement or death of the most prolific taxonomists and the failure of their students to obtain employment as systematists in those regions. Similar trends have been noted for many other groups of understudied organisms (Rodman \& Cody 2003; Agnarsson \& Kuntner 2007).

Increasing restrictions on export of specimens from many megadiverse and understudied countries have also made it increasingly difficult for European and North American researchers to obtain specimens from regions of high biodiversity (Paknia et al. 2015; Audisio 2017). This may be mitigated to some extent by increased investment by developing countries in basic biodiversity research as well as increases in international collaboration. Although our data indicate that papers co-authored by researchers from different continents remain a small minority of total publications, there is a clear trend toward increasing international co-authorship in the most recent decade. This trend may also reflect the impacts of recent 

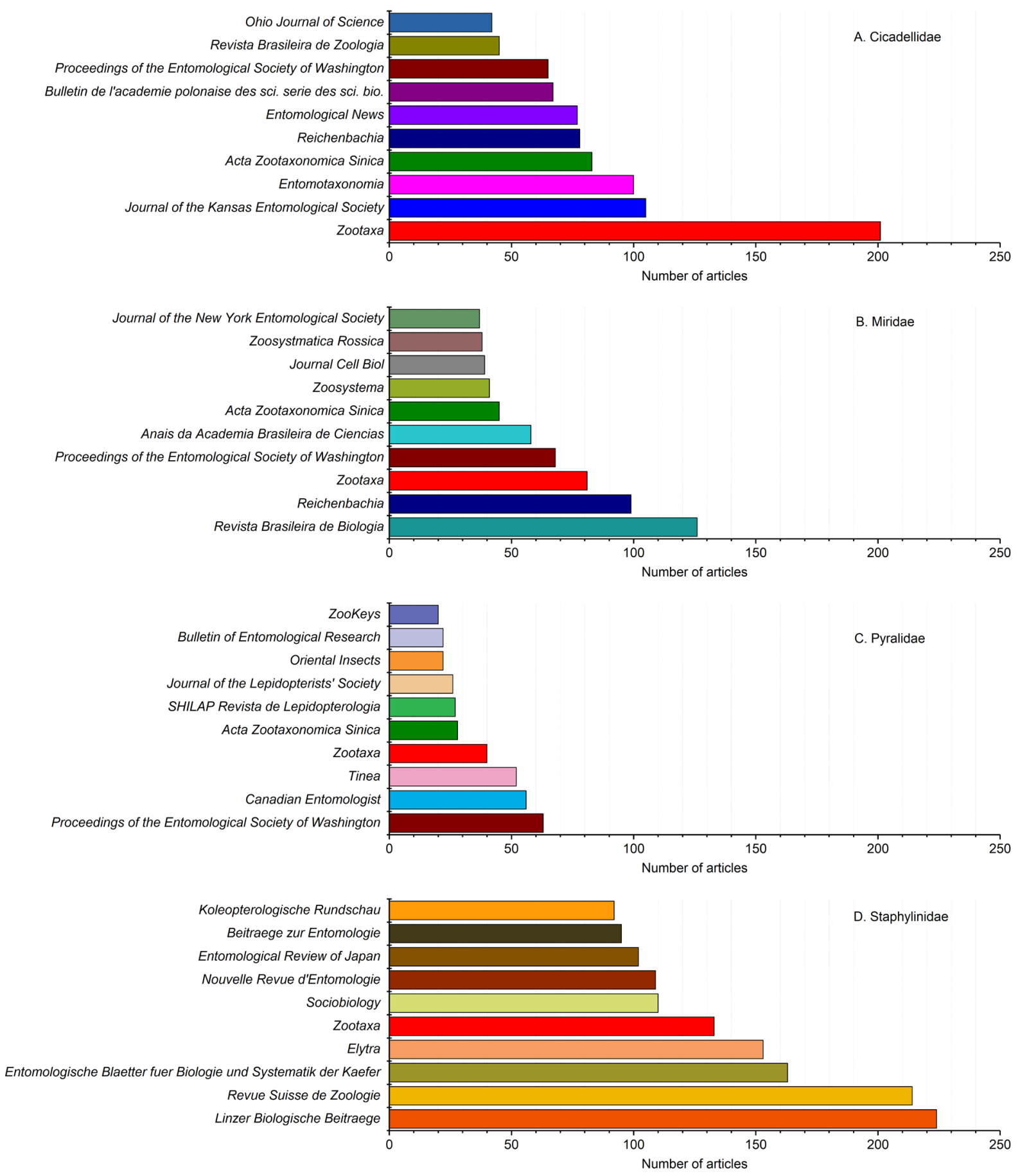

Fig 9. Top 10 of most utilized journals from 1946 to 2012. A. Cicadellidae. B. Miridae. C. Pyralidae. D. Staphylinidae. 
government-funded programs (e.g., in China and several South American countries) that promote international collaboration. Such internationalization of taxonomic research has the potential to greatly improve exchange of new ideas and technologies that further enhance taxonomic productivity worldwide.

Among the groups examined, total taxonomic output was highest for Staphylinidae, but the average length of papers declined overall. The total article length for the other three families showed only slight trends with average length declining for Cicadellidae and increasing for Pyralidae. This may reflect different states of overall knowledge of the diversity of these groups, with Pyralidae better known and, therefore, with greater recent emphasis on synthetic revisionary studies in this group compared to the other less well-known groups (Katiyar 1964; Khan et al. 2011). This may also reflect a predominance of mid- to late-career researchers working on Miridae and Pyralidae who are better able to publish more comprehensive studies. In contrast, the communities working on Cicadellidae and Staphylinidae are currently dominated by younger, early-career scientists who tend to publish larger numbers of short papers. Academic promotion criteria in some countries continue to reward researchers who produce large numbers of publications at the expense of larger synthetic works (Shao \& Shen 2011, 2012; Cao et al. 2013). This agrees with the findings of Tancoigne \& Dubois (2013) who analyzed the Zoological Record between 1978 and 2011 and found a decline in species descriptions per author and fewer species per publication. A similar trend was also found in plant taxonomy (Treurnicht et al. 2017).

Tancoigne \& Dubois (2013) found that fewer journals are publishing articles on systematics or description of new species/subspecies, a trend they considered to be a modification of the 'publication landscape', not a sign of a decline in taxonomy. For three of the four groups examined here, regional journals (reflecting the geographic locations and institutional affiliations of authors) or those focused on particular insect orders (reflecting the organismal focus of the author), continued to predominate. Zootaxa is currently the most utilized animal taxonomic journal overall, but was only the most utilized publication venue for one of the four families examined (Cicadellidae).

The 2425 taxonomic papers (including books) published during the period 1946 to 2012 for Cicadellidae, 2980 for Miridae, 4683 for Pyralidae and 4765 for Staphylinidae are nearly all traditional taxonomic articles comprising morphology-based descriptions and keys. In recent years, taxonomists have increasingly incorporated molecular data and phylogenetic methods into their work and, at the same time, have somewhat de-emphasized morphology-based taxonomy (Adams 1972; Benoît 2005; Hebert \& Gregory 2005; Scheffers et al. 2012; Liu et al. 2015; Wang et al. 2017). This may partly explain why taxonomic productivity, as measured by new species described, for three of the four groups examined remains below historic highs, despite the large numbers of new systematists being trained. Another possible explanation is that new taxa are becoming increasingly difficult to find compared with the period between 1960s and 1980s (Fig. 1) or have small geographic ranges (Scheffers et al. 2012; Pimm et al. 2014), although this is contradicted by the recent exponential growth in species discovery for three of the four groups examined. It seems more likely that the effects of taxonomic training programs have had uneven impact across taxa (e.g., the three investigated groups in this study), particularly in groups for which no taxonomic expertise currently exists.

Despite the establishment of programs to promote taxonomic training and comprehensive revisionary studies, and a slight increase in overall taxonomic output, we found no evidence to suggest that taxonomic productivity, in terms of output per individual researcher, has increased over its historic average for the insect families examined. Many insect taxonomists now working are still very early in their careers and/ or have many other job responsibilities besides taxonomic research (Joppa et al. 2011), there is still a shortage of taxonomists (Rodrigues et al. 2010; Pearson et al. 2011; Bacher 2012; Joppa et al. 2012; Paknia et al. 2015) and funding in support of taxonomy remains modest compared to that devoted to some other biological sub-disciplines (Godfray 2002). As noted recently (Grieneisen et al. 2014), 
completely documenting all species on Earth will require at least an additional 400 years based on current rates of species discovery and description. Because this timeframe is obviously unacceptable, given ongoing habitat degradation and extinction, taxonomic productivity needs to be increased dramatically. Although we are encouraged by the overall recent trends toward increasing productivity indicated by our analysis for the insect taxa examined, it remains to be seen whether these increases can be sustained or accelerated. It will, therefore, be important to continue tracking progress in biodiversity discovery, particularly for understudied megadiverse groups like insects, both to identify deficiencies and gaps in knowledge, and to promote wider adoption of more efficient research practices and workflows.

\section{Conclusions}

Publishing trends in insect taxonomy from 1946 through 2012 were analyzed based on detailed examination of four diverse families to elucidate the recent progress and current status of insect taxonomy. Publications on four diverse insect families: Cicadellidae (leafhoppers), Miridae (plant bugs), Pyralidae (moths) and Staphylinidae (rove beetles) that are included in the Zoological Record online literature database. These data were analyzed on a yearly basis in many aspects of new species, article length, species description length, authorship and collaborations, and taxonomic journals. The results showed a trend toward increasing numbers of taxonomic papers published and new species described per year until around 1980, followed by a steep decline and subsequent partial recovery. The number of papers describing new species generally reflects the trend in numbers of new species, and there is still a shortage of synthetic works (monographs) containing descriptions of many species as well as keys and phylogenetic analyses. Researchers from Europe and North America continue to produce the most taxonomic research on three of the four families, but contributions from Asia and South America have increased in recent years for all groups examined. In contrast to the other families, the main center for Cicadellidae taxonomy has recently shifted to Asia. Collaborative research within and across continents is increasing as reflected by the increased authorship of the publications. While the overall trend toward increasing rates of species discovery is encouraging, it is still not sufficient to complete the task of completing a global faunistic inventory in a reasonable timeframe.

\section{Acknowledgements}

The source data used and analyzed were retrieved from the Zoological Record. We thank Dr. Hailong He for his comments on this paper. We are grateful to several anonymous referees for critical comments that greatly improved previous versions of the manuscript. This study was supported in part by the Opening Foundation of Key Laboratory of Resource Biology and Biotechnology in Western China (Northwest University), the Ministry of Education (No. ZSK2017005), the National Natural Science Foundation of China (NSFC No. 31401998), the Natural Science Foundation of Shaanxi Province (2014JQ3085), the Northwest University (doctoral start-up funding) and the West Light Foundation of the Chinese Academy of Sciences (for Yang Liu).

\section{Authors' contributions}

LY carried out the analyses and drafted the manuscript. LY and CD designed the study. LY, SB, and YW retrieved and analyzed the data. $\mathrm{CD}, \mathrm{SB}$ and $\mathrm{YW}$ improved subsequent versions of the manuscript. All authors read and approved the final manuscript.

\section{References}

Adams E.N. III. 1972. Consensus techniques and the comparison of taxonomic trees. Systematic Biology 21:390-397. https://doi.org/10.1093/sysbio/21.4.390

Agnarsson I. \& Kuntner M. 2007. Taxonomy in a changing world: seeking solutions for a science in crisis. Systematic Biology 56: 531-539. https://doi.org/10.1080/10635150701424546 
Audisio P. 2017. Insect taxonomy, biodiversity research and the new taxonomic impediments. Fragmenta Entomologica 49: 121-124.

Bacher S. 2012. Still not enough taxonomists: reply to Joppa et al. Trends in Ecology \& Evolution 27: 65-66. https://doi.org/10.1016/j.tree.2011.11.003

Backus E.A., Serrano M.S. \& Ranger C.M. 2005. Mechanisms of hopperburn: an overview of insect taxonomy, behavior, and physiology. Annual Review of Entomology 50: 125-151.

https://doi.org/10.1146/annurev.ento.49.061802.123310

Benoît D. 2005. Towards integrative taxonomy. Biological Journal of the Linnean Society 85: 407-415. https://doi.org/10.1111/j.1095-8312.2005.00503.x

Cao C., Li N., Li X. \& Liu L. 2013. Reforming China’s S\&T system. Science 341: 460-462. https://doi.org/10.1126/science.1234206

Cao Y., Dmitriev D.A. \& Zhang Y. 2018. New species of the leafhopper genera Kusala Dworakowska and Diomma Motschulsky (Hemiptera: Cicadellidae: Typhlocybinae: Erythroneurini) with description of a new subgenus. Zootaxa 4514 (2): 263-272. https://doi.org/10.11646/zootaxa.4514.2.9

Cassis G. \& Schuh R.T. 2012. Systematics, biodiversity, biogeography, and host associations of the Miridae (Insecta: Hemiptera: Heteroptera: Cimicomorpha). Annual Review of Entomology 57: 377-404. https://doi.org/10.1146/annurev-ento-121510-133533

Cassis G., Wall M.A. \& Schuh R.T. 2007. Insect biodiversity and industrialising the taxonomic process: the plant bug case study (Insecta: Heteroptera: Miridae). Systematics Association Special Volume 72: $193-212$.

Chapman A.D. 2009. Numbers of living Species in Australia and the World. $2^{\text {nd }}$ Edition, Report for the Australian Biological Resources Study, Canberra.

Dietrich C.H. 2013. Overview of the phylogeny, taxonomy and diversity of the leafhopper (Hemiptera: Auchenorrhyncha: Cicadomorpha: Membracoidea: Cicadellidae) vectors of plant pathogens. Proceedings of the 2013 International Symposium on Insect Vectors and Insect-Borne Diseases: 47-70. Special Publication of Taiwan Agricultural Research Institute 173, Taichung, Taiwan.

Dietrich C.H. \& Dmitriev D.A. 2016. Insect phylogenetics in the digital age. Current Opinion in Insect Science 18: 48-52.

Dmitriev D.A. \& Dietrich C.H. 2010. Review of the species of New World Erythroneurini (Hemiptera: Cicadellidae: Typhlocybinae). IV. Genus Eratoneura. Illinois Natural History Survey Bulletin 39: 80258.

Erwin T.L. 1982. Tropical forests: their richness in Coleoptera and other arthropod species. Coleopterists Bulletin 36: 74-75.

Erwin T.L. 1997. Biodiversity at its utmost: tropical forest beetles. In: Reaka-Kudla M., Wilson D. \& Wilson E. (eds) Biodiversity II: Understanding and Protecting our biological Resources: 27-40. National Academies Press, Washington DC. https://doi.org/10.17226/4901

Feng L., Dietrich C.H. \& Zhang Y. 2018. Two new species of Sochinsogonia (Hemiptera: Cicadellidae: Cicadellinae) from Philippines. Zootaxa 4486 (3): 340-348. https://doi.org/10.11646/zootaxa.4486.3.6

Frank J.H. \& Ahn K.-J. 2011. Coastal Staphylinidae (Coleoptera): a worldwide checklist, biogeography and natural history. ZooKeys 107: 1-98. https://doi.org/10.3897/zookeys.107.1651

Gaston K.J. \& May R.M. 1992. Taxonomy of taxonomists. Nature 356: 281.

https://doi.org/10.1038/356281a0 
LIU Y. et al., Publishing trends and productivity in insect taxonomy

Gaston K.J. \& O’Neill M.A. 2004. Automated species identification: why not? Philosophical Transactions of the Royal Society of London, Series B: Biological Sciences 359: 655-667.

https://doi.org/10.1098/rstb.2003.1442

Godfray H.C.J. 2002. Challenges for taxonomy. Nature 417: 17. https://doi.org/10.1038/417017a

Grieneisen M.L., Zhan Y., Potter D. \& Zhang M. 2014. Biodiversity, taxonomic infrastructure, international collaboration, and new species discovery. Bioscience 64: 322-332.

https://doi.org/10.1093/biosci/biu035

Hamilton K.G.A. 1983. Revision of the Macripsini and Neopsini of the New-World (Rhynchota: Homoptera: Cicadellidae) with notes on intersex morphology. Memoirs of the Entomological Society of Canada 123: 1-223.

Hebert P.D.N. \& Gregory T.R. 2005. The promise of DNA barcoding for taxonomy. Systematic Biology 54: 852-859. https://doi.org/10.1080/10635150500354886

Hopkins G.W. \& Freckleton R.P. 2002. Declines in the numbers of amateur and professional taxonomists: implications for conservation. Animal Conservation 5: 245-249.

https://doi.org/10.1017/S1367943002002299

Joppa L.N., Roberts D.L. \& Pimm S.L. 2011. The population ecology and social behaviour of taxonomists. Trends in Ecology \& Evolution 26: 551-553. https://doi.org/10.1016/j.tree.2011.07.010

Joppa L.N., Roberts D.L. \& Pimm S.L. 2012. Taxonomy that matters: response to Bacher. Trends in Ecology \& Evolution 27: 66. https://doi.org/10.1016/j.tree.2011.11.015

Katiyar R. 1964. Bibliography on the genus Chilo Zincken (Lepidoptera: Pyralidae). Contributions to Entomology 14: 125-154. https://doi.org/10.21248/contrib.entomol.14.1-2.125-154

Khan Z.R., Barrion A.T., Litsinger J.A., Castilla N.P. \& Joshi R.C. 2011. A bibliography of rice leaffolders (Lepidoptera: Pyralidae). Insect Science and Its Application 9: 129-174.

https://doi.org/10.1017/S1742758400005919

Liu Y., Xue H. \& Yang X. 2015. Advances in Systematics of Chinese Mordellidae (Coleoptera): 865870. Chinese Academy of Sciences, Beijing. [In Chinese with English abstract.]

Liu Y., Erwin T.L., Yang X. \& Zhao Y. 2018. Mordellidae (Coleoptera) research: a review based on the Zoological Record between 1864 and 2013. Insects 9 (3): 113. https://doi.org/10.3390/insects9030113

Nielson M.W. 1975. A revision of the subfamily Coelidiinae (Homoptera: Cicadellidae). Tribes Tinobregmini, Sandersellini and Tharrini. Bulletin of the British Museum (Natural History), Entomology 24: 1-197.

Nielson M.W. 1977. A Revision of the Subfamily Coelidiinae (Homoptera: Cicadellidae). II. Tribe Thagriini. Pacific Insects Monograph 34, Bishop Museum, Honolulu.

Nielson M.W. 1979. A Revision of the Subfamily Coelidiinae (Homoptera: Cicadellidae). III. Tribe Teruliini. Pacific Insects Monograph 35, Bishop Museum, Honolulu.

Nielson MW. 1982. A Revision of the Subfamily Coelidiinae (Homoptera: Cicadellidae). III. Tribe Coelidiini. Pacific Insects Monograph 38, Bishop Museum, Honolulu.

Novotny V., Basset Y., Miller S.E., Weiblen G.D., Bremer B., Cizek L. \& Drozd P. 2002. Low host specificity of herbivorous insects in a tropical forest. Nature 416: 841. https://doi.org/10.1038/416841a

Oberprieler R.G., Marvaldi A.E. \& Anderson R.S. 2007. Weevils, weevils, weevils everywhere. Zootaxa 520: 491-520. 
Paknia O., Rajaei S.H. \& Koch A. 2015. Lack of well-maintained natural history collections and taxonomists in megadiverse developing countries hampers global biodiversity exploration. Organisms Diversity \& Evolution 15: 619-629. https://doi.org/10.1007/s13127-015-0202-1

Pearson D.L., Hamilton A.L. \& Erwin T.L. 2011. Recovery plan for the endangered taxonomy profession. Bioscience 61: 58-63. https://doi.org/10.1525/bio.2011.61.1.11

Pimm S.L., Jenkins C.N., Abell R., Brooks T.M., Gittleman J.L., Joppa L.N., Raven P.H., Roberts C.M. \& Sexton J.O. 2014. The biodiversity of species and their rates of extinction, distribution, and protection. Science 344. https://doi.org/10.1126/science.1246752

Rodman J.E. \& Cody J.H. 2003. The taxonomic impediment overcome: NSF's partnerships for enhancing expertise in taxonomy (PEET) as a Model. Systematic Biology 52: 428-435.

Rodrigues A.S.L., Gray C.L., Crowter B.J., Ewers R.M., Stuart S.N., Whitten T. \& Manica A. 2010. A global assessment of amphibian taxonomic effort and expertise. Bioscience 60: 798-806.

https://doi.org/10.1525/bio.2010.60.10.6

Scheffers B.R., Joppa L.N., Pimm S.L. \& Laurance W.F. 2012. What we know and don't know about Earth's missing biodiversity. Trends in Ecology \& Evolution 27: 501-510.

https://doi.org/10.1016/j.tree.2012.05.008

Shao J. \& Shen H. 2011. The outflow of academic papers from China: why is it happening and can it be stemmed? Learned Publishing 24: 95-97. https://doi.org/10.1087/20110203

Shao J. \& Shen H. 2012. Research assessment and monetary rewards: the overemphasized impact factor in China. Research Evaluation 21: 199-203. https://doi.org/10.1093/reseval/rvs011

Tancoigne E. \& Dubois A. 2013. Taxonomy: no decline, but inertia. Cladistics 29: 567-570. https://doi.org/10.1111/cla.12019

Tancoigne E., Bole C., Sigogneau A. \& Dubois A. 2011. Insights from Zootaxa on potential trends in zoological taxonomic activity. Frontiers in Zoology 8: 5. https://doi.org/10.1186/1742-9994-8-5

Tancoigne E., Barbier M., Cointet J.P. \& Richard G. 2014. The place of agricultural sciences in the literature on ecosystem services. Ecosystem Services 10: 35-48. https://doi.org/10.1016/j.ecoser.2014.07.004

Treurnicht M., Colville J.F., Joppa L.N., Huyser O. \& Manning J. 2017. Counting complete? Finalising the plant inventory of a global biodiversity hotspot. PeerJ 5: e2984. https://doi.org/10.7717/peerj.2984

Van Emden F.L. 1957. The taxonomic significance of the characters of immature insects. Annual Review of Entomology 2: 91-106. https://doi.org/10.1146/annurev.en.02.010157.000515

Wang Y., Dietrich C.H. \& Zhang Y. 2017. Phylogeny and historical biogeography of leafhopper subfamily Evacanthinae (Hemiptera: Cicadellidae) based on morphological and molecular data. Scientific Reports 7: 45387. https://doi.org/10.1038/srep45387

Xue Q., Mckamey S.H. \& Zhang Y. 2017a. A new species of the endemic Chilean leafhopper genus Chileanoscopus (Hemiptera: Cicadellidae: Idiocerinae). Zootaxa 4237 (3): 567-573.

https://doi.org/10.11646/zootaxa.4237.3.6

Xue Q., Mckamey S.H. \& Zhang Y. 2017b. Philippogalla, a new genus for Philipposcopus modestus (Baker) from the Philippines, and a new species of Philipposcopus (Hemiptera: Cicadellidae: Idiocerinae) from China. Zootaxa 4291 (1): 034-040. https://doi.org/10.11646/zootaxa.4291.1.2

Xue Q., Mckamey S.H. \& Zhang Y. 2017c. Redescription of the Philippine leafhopper genus Iposcopus Baker (Hemiptera: Cicadellidae: Idiocerinae). Zootaxa 4277 (1): 122-128.

https://doi.org/10.11646/zootaxa.4277.1.9 
LIU Y. et al., Publishing trends and productivity in insect taxonomy

Xue Q., Mckamey S.H. \& Zhang Y. 2017d. Taxonomic revision of the Malaysian Idiocerinae (Hemiptera: Cicadellidae), with description of new taxa. Zootaxa 4226 (3): 405-428 https://doi.org/10.11646/zootaxa.4226.3.5

Young D.A. 1977. Taxonomic study of the Cicadellinae (Homoptera: Cicadellidae). Part 2. New World Cicadellini and the genus Cicadella. North Carolina Agricultural Experiment Station Technical Bulletin 239: $1-1135$.

Young D.A. 1986. Taxonomic study of the Cicadellinae (Homoptera: Cicadellidae). Part 3. Old World Cicadellini. North Carolina Agricultural Experiment Station Technical Bulletin 281: 1-639.

Zahniser J.N. \& Dietrich C.H. 2013. A review of the tribes of Deltocephalinae (Hemiptera: Auchenorrhyncha: Cicadellidae). European Journal of Taxonomy 45: 1-211.

https://doi.org/10.5852/ejt.2013.45

Manuscript received: 18 October 2018

Manuscript accepted: 22 January 2019

Published on: 7 March 2019

Topic editor: Gavin Broad

Desk editors: Kristiaan Hoedemakers \& Jeroen Venderickx

Printed versions of all papers are also deposited in the libraries of the institutes that are members of the EJT consortium: Muséum national d'Histoire naturelle, Paris, France; Meise Botanic Garden, Belgium; Royal Museum for Central Africa, Tervuren, Belgium; Royal Belgian Institute of Natural Sciences, Brussels, Belgium; Natural History Museum of Denmark, Copenhagen, Denmark; Naturalis Biodiversity Center, Leiden, the Netherlands; Museo Nacional de Ciencias Naturales-CSIC, Madrid, Spain; Real Jardín Botánico de Madrid CSIC, Spain; Zoological Research Museum Alexander Koenig, Bonn, Germany. 


\section{Appendix}

\section{Descriptions of the four families for analysis:}

Cicadellidae (leafhoppers) is among the largest families of plant-feeding herbivores and the largest family of order Hemiptera (Dietrich 2013). With $>21000$ described species, Cicadellidae includes more known species than birds, mammals, reptiles and amphibians combined. Cicadellidae are widely distributed worldwide, from tropical rainforests to arctic tundra and from sea level to above $4000 \mathrm{~m}$ (>13123 ft). Cicadellidae feed by sucking the sap of vascular plants, may transmit plant pathogens (e.g., phytoplasmas, viruses or bacteria) and cause major economic losses to field crops, fruit trees etc. Several leafhopper species therefore are important agricultural pests (Backus et al. 2005).

Miridae (plant bugs, leaf bugs and grass bugs) is the most species-rich family of true bugs (hemipteran suborder Heteroptera), with approximately 11020 described species (Cassis et al. 2007; Cassis \& Schuh 2012). Miridae are widely distributed and several species are notorious agricultural pests that pierce plant tissues, feed on the sap, and sometimes transmit viral plant diseases. Other species, however, are predatory. Despite their economic importance mirids are little studied outside heteropterological circles (Cassis \& Schuh 2012).

Pyralidae (snout moths) is one of the largest families in the Lepidoptera, with 5 subfamilies and over 6000 described species distributed worldwide. Most of these small moths are inconspicuous. Several species are known as pests of field crops and stored products (e.g., grains, spices, flour, bulk fruits or vegetables). The family also includes wax moths (subfamily Galleriinae), which consume honeycomb and are pests of beehives, but are also bred in large numbers as live food for small pets, and for fishing bait. The family of Pyralidae is now variously split into the Crambidae.

The Staphylinidae (rove beetles) are omnivorous and, although some may be natural enemies of certain insect pests, this group is not generally considered to be of economic importance. Nevertheless, this is the largest beetle family, and they are an ecologically and morphologically diverse group of beetles commonly encountered in most terrestrial ecosystems, primarily distinguished by their short elytra that leave more than half of the abdomen exposed. There are approximately 58000 described species in thousands of genera. It is also an ancient group, with fossil rove beetles known from the Triassic (200 million years ago). Frank \& Ahn (2011) published a worldwide checklist, biogeography and natural history of Staphylinidae. 